\title{
O Impacto da Governança Corporativa: Conselho de Administração, Estrutura de Propriedade e Controle e as Informações Socioambientais nas Companhias Abertas
}

\author{
Thamirys de Sousa Correia \\ Universidade Federal da Paraíba - Brasil \\ thamirys_correia@hotmail.com \\ http://orcid.org/oooo-0002-2924-4434 \\ Ingrid Laís de Sena Costa \\ Universidade Federal da Paraíba - Brasil \\ ilsenna2.o@gmail.com \\ Wenner Glaucio Lopes Lucena \\ Universidade Federal da Paraíba - Brasil \\ wdlucena@yahoo.com.br
}

\section{Resumo}

O estudo teve por objetivo analisar o impacto da Governança Corporativa (representada pelo Conselho de Administração e Estrutura de Propriedade e Controle) no disclosure voluntário das Informações Socioambientais das companhias de capital aberto no mercado brasileiro. Quanto a metodologia, a amostra foi composta por 204 empresas listadas na Bolsa de Mercadorias \& Futuros e Bolsa de Valores de São Paulo no período de 2010 a 2015, onde os dados foram coletados por meio dos formulários de referência divulgado pelas companhias, sites das próprias companhias, site da Comissão de Valores Mobiliários (CVM) e banco de dados da Economática ${ }^{\circledR}$. Com isso, nos resultados analisados por meio da Regressão Logística Binária, foram identificadas que, apenas $47 \%$ das empresas selecionadas divulgaram as Informações Socioambientais. Ao passo que a não dualidade do profissional que atua como CEO e presidente do Conselho de Administração, é um aspecto imprescindível da Governança Corporativa para que haja divulgação de Informações Socioambientais das companhias abertas. Todavia, na variável Participação do Controlador, apesar de serem verificadas significância estatísticas, foram observadas relações negativa, sendo a possível justificativa o fato de que a adoção obrigatória das IFRS para as empresas abertas em 2010, no Brasil, pode ter impactado na disponibilização de Informações 
Socioambientais mesmo que os controladores das organizações selecionadas possuíssem mais que $50 \%$ das ações com direito ao voto.

Palavras chave: conselho de administração, estrutura de propriedade, divulgação, informações socioambientais 
The Impact of Corporate Governance: Board of Directors, Ownership Structure and Control and the Socioenvironmental Information on Listed Companies

\author{
Thamirys de Sousa Correia \\ Universidade Federal da Paraíba - Brasil \\ thamirys_correia@hotmail.com \\ http://orcid.org/oooo-0002-2924-4434 \\ Ingrid Laís de Sena Costa \\ Universidade Federal da Paraíba - Brasil \\ ilsenna2.0@gmail.com \\ Wenner Glaucio Lopes Lucena \\ Universidade Federal da Paraíba - Brasil \\ wdlucena@yahoo.com.br
}

\begin{abstract}
The objective of the study was to analyze the impact of Corporate Governance (represented by the Board of Directors and Structure of Ownership and Control) in the voluntary disclosure of Socioenvironmental Information of publicly traded companies in the Brazilian market. As for the methodology, the sample was composed of 204 companies listed on the Brazilian Mercantile \& Futures Exchange and São Paulo Stock Exchange in the period from 2010 to 2015 , where the data were collected through the reference forms published by the companies, website of the companies, the website of the Brazilian Securities and Exchange Commission (CVM) and the Economática $®$ database. Thus, in the results analyzed through the Binary Logistic Regression, it was identified that only $47 \%$ of the selected companies disclosed the Socioenvironmental Information. Whereas, the non-duality of the professional who acts as CEO and Chairman of the Board of Directors, is essential aspect of Corporate Governance so that there is disclosure of Socio-environmental Information of publicly held companies. However, in the variable Participation of the Controller, although statistical significance was verified, negative relations were observed, the possible justification being the fact that the mandatory adoption of IFRS for companies opened in 2010, In Brazil, may have impacted on the availability of Socioenvironmental Information even if the controllers of the selected organizations had more than $50 \%$ of the voting shares.
\end{abstract}


Teoria e Prática em Administração, volume 7, número 2, 2017 O Impacto da Governança Corporativa: Conselho de Administração, Estrutura de Propriedade e Controle e as Informações Socioambientais na Companhias Abertas Correia, Costa \& Lucena
p. $156-182$

DOI: http://dx.doi.org/10.21714/2238-104X2017v7i2-3317 Submissão: 06/Mar/2017 -Segunda versão: 23/Ago/2017 -Aceite: 29/Ago/2017

Keywords: board of directors, ownership structure, disclosure, socioenvironmental information 
No contexto empresarial atual o Conselho de Administração tem um papel importante na tomada de decisões das empresas com relação a gestão e definição de estratégias que busquem a maximização dos rendimentos dos acionistas, bem como na valorização dos ativos. Assim, o conselho, tem o poder de contratar, demitir e compensar a alta administração, no intuito de resolver conflitos de interesse entre os tomadores de decisão e os proprietários das empresas. Além disso, minimiza os custos de agência associados com a separação da propriedade e do controle, auxiliando na sobrevivência das organizações, bem como intervêm nas informações a serem divulgadas voluntariamente pelas companhias (Jensen \& Meckling, 1976; Williamson, 1983; Baysinger \& Butler, 1985; Aranha, Rossoni \& Mendes-da-Silva, 2016).

De acordo com o que se espera o conselho de administração pode influenciar as decisões de disclosure voluntário das companhias, em especial na divulgação de Informações Socioambientais, nesse sentido, como os gestores e controladores possuem informações adicionais que não tem obrigatoriedade de serem evidenciadas, em um mercado de fraco monitoramento, como é o caso do mercado brasileiro, a evidenciação de tais informações podem impactar diretamente à qualidade da informação contábil, além da divulgação destas (Holtz \& Sarlo, 2014; Bezerra, Lustosa, Sales, \& Fernandes, 2015).

Além disso, a estrutura de propriedade e controle é destacada como um dos fatores determinantes da divulgação de informações sobre a sustentabilidade das firmas (Ghazali, 2007). Na qual, na pesquisa de Ghazali (2007) foi verificada que, mesmo entre as maiores ações ativamente negociadas na Malásia, há uma variabilidade considerável de atividades sociais divulgadas em relatórios corporativos. Ao passo que, as empresas nas quais os conselheiros detêm uma maior proporção de ações (empresas administradas pelo proprietário) divulgaram significativamente menos Informações Socioambientais, enquanto que, as firmas em que o governo é um acionista relevante divulgaram mais tais informações nos seus relatórios anuais.

Com isso, verifica-se que a disponibilização dos relatórios de Informações Socioambientais vêm recebendo grande atenção, tanto em reuniões acadêmicas, quanto em círculos políticos ao redor do mundo. Em que, o maior interesse pela sua divulgação decorre do advento da Globalização e comércio internacional, que têm refletido no aumento da complexidade dos negócios, além das novas exigências de maior transparência (Jamali, Asem \& Myriam, 2008; Soliman, El Din, e Sakr, 2012). 
Á exemplo, na Malásia, há quatro dimensões para que as empresas definam suas estratégias e objetivos de sustentabilidade, são elas: a comunidade, que se refere ao o engajamento das atividades envolvendo as comunidades, incluindo apoio à educação, doações e programas para a juventude, com o objetivo de criar laços com a sociedade; local de trabalho, para manter uma maior produtividade dos funcionários, incluindo a qualidade do ambiente de trabalho, saúde e segurança humana, além de seus direitos; mercado, pela formulação de atividades visando incentivar as partes interessadas, acionistas, fornecedores, vendedores e clientes a agir de forma sustentável por meio das relações de cadeia de valor; e, ambiental pelas políticas e atividades que envolvam questões sobre energia, biocombustíveis, biodiversidade, preservação da flora e da fauna (Yusoff, Jamal, \& Darus, 2016).

Com base no exposto, há contribuição no estudo sobre as relações entre o conselho de administração, a estrutura de propriedade e o disclosure voluntário das Informações Socioambientais, visto que os gestores e os proprietários assumem a responsabilidade perante a sociedade no que se refere ao meio ambiente, a sustentabilidade, bem com a divulgação das informações aos diversos usuários interessados no assunto (Crisóstomo, Freire \& Parente, 2013; Almeida et al., 2015). Dessa forma, a presente pesquisa se torna relevante, justamente por apresentar uma investigação mais completa, em um período mais amplo para análises.

Nessa perspectiva, o objetivo da pesquisa é analisar qual o impacto da Governança Corporativa (representada pelo conselho de administração e estrutura de propriedade e controle) no disclosure voluntário das Informações Socioambientais de empresas brasileiras que negociam na Bolsa de Mercadorias \& Futuros e Bolsa de Valores de São Paulo (BM\&FBovespa), no período de 2010 a 2015.

\section{Referencial Teórico}

\section{Disclosure Voluntário Socioambiental}

O disclosure voluntário é uma temática bastante discutida no mercado de capitais (Guimarães, 2011; Clarkson, Fang, Li, \& Richardson, 2013; Plumlee, Brown, Hayes, \& Marshall, 2015). Na qual, Verrecchia (2001) apresenta uma discussão acerca dos modelos desenvolvidos pela teoria da divulgação para explicar e prever os fenômenos relacionados 
ao assunto. Nessa pesquisa, é apresentada uma classificação das pesquisas em três categorias elencadas a seguir:

- $\quad$ A primeira refere-se a Divulgação baseada em associação que busca analisar os efeitos do disclosure nos agentes;

- A segunda, a Divulgação é baseada em julgamento que analisa a discricionariedade que os gerentes exercem em relação ao disclosure;

- A terceira, a Divulgação é baseada na eficiência e analisa quais configurações do disclosure são preferidas.

Diante disso, o presente este estudo se classifica dentro da segunda categoria proposta por Verrecchia (2001). Visto que, para Verrecchia (2001) ainda não há uma teoria unificada e consistente capaz de esclarecer a divulgação voluntária, havendo apenas uma mescla de teorias contábeis, econômicas e financeiras.

Ainda no âmbito internacional, Hughes e Pae (2004) e Pae (2005) pesquisam sobre disclosure. Bem como Dye (2001), na qual acredita que a teoria de disclosure voluntário está relacionada a necessidade que as empresas tem de evidenciar informações que sejam favoráveis aos objetivos da entidade.

$\mathrm{Na}$ decisão empresarial de divulgar informações socioambientais, deve-se verificar quais informações são imprescindíveis ao mercado financeiro e sociedade. Dessa forma, precisa-se que haja um equilíbrio para atender aos interesses dos envolvidos, ou seja, investidores e analistas financeiros, além de adquirir condições de decidir sobre alocação de recursos, pois é preciso verificar a relação do custo-benefício do disclosure voluntário (Verrecchia, 2001; Comier \& Magnan, 2015).

Diante disso, a responsabilidade socioambiental das firmas para atendar à sociedade, é um aspecto importante para a sobrevivência destas. Do mesmo modo que, esta prática não deve ser evidenciada apenas para realização de marketing, mas também por questões de ética no comportamento das empresas e dos stakeholders, ou seja, observa-se que as ações sobre a responsabilidade social são divulgadas, nos balanços sociais, no que tange à informações quantitativas sobre as ações das empresas, além dos relatórios de sustentabilidade, com dados qualitativas sobre os projetos sociais (Igarashi, Igarashi, Lima, Dalbello, \& Hercos, 2010; Almeida et al., 2015).

Em pesquisas realizadas no Brasil sobre o tema, Schultz, Marques, Murcia, e Hofer, (2012) investigaram o disclosure voluntário em cooperativas agropecuárias comparativamente a empresas de capital aberto do setor agropecuário no período de 2008 , 
identificando que as cooperativas apresentaram um maior nível de disclosure de informações voluntárias referentes à questões ambientais e sociais já as companhias de capital aberto apresentaram maior nível de divulgação com relação a informações econômicas.

Além de Schultz, et al., (2012), Sousa, Silva, Ribeiro, e Weffort, (2014) também evidenciou estudos sobre o disclosure voluntário, na qual, analisou a relação do valor de mercado e o disclosure de informações referentes a questões econômicas, ambientais e sociais nos relatórios de companhias abertas entre 2007 e 2011. Constatando uma relação significativa e positiva com relação as informações econômicas e negativa com relação as informações ambientais.

No mercado brasileiro também há exemplos de relações positivas da sustentabilidade com aspectos relacionados com a governança corporativa, a exemplo de características como dualidade do CEO, controle familiar em empresas, além de aspectos da estrutura organizacional como porte, ou seja, companhias de maior porte tendem a divulga um número de informações maior sobre sustentabilidade (Bomfim, Teixeira, \& Monte, 2015).

\section{Conselho de Administração}

Devido à ocorrência dos conflitos de interesse a assimetria de informação pode prejudicar o funcionamento dos mercados e a relação entre o principal (Proprietário) e o agente (Gestor) (Coutinho, Amaral \& Bertucci, 2006). Nesse contexto, um dos intuitos da Governança Corporativa é diminuir a assimetria da informação, reduzindo os conflitos de agência, em que, a composição do conselho de administração, a estrutura de propriedade e controle, a transparência (Disclosure), bem como a proteção aos acionistas minoritários são elementos fundamentais (Bebchuk \& Weisbach, 2010; L. F. Correia, Amaral, \& Luvet., 2011; Claessens \& Yurtoglu, 2013; Caixe \& Krauter, 2013).

Dessa maneira, condizendo com a Lei n ${ }^{0} 6.404$ (1976), autores como Silveira e Barros (2008), Tzioumis (2008); L. F. Correia, et al. (2011), Bebchuk e Weisbach (2011), Qin (2012); Claessens e Yurtoglu (2013), P. R. Cunha e Politelo (2013), Khan, Muttakin, e Siddiqui (2013), Jizi, Salama, Dixon, \& Stratling (2014); Alfraih (2016) e Torchia \& Calabrò (2016) determinam que o Conselho de Administração deve levar em consideração sua integridade, tamanho e a prestação de contas da organização e de sua gestão, incluindo a supervisão e a orientação da diretoria. 
Sobre a composição do conselho de administração, o elevado número de conselheiros pode causar problemas de comunicação, o que permite o domínio do agente, além de favorecer o surgimento de conflitos internos, devido a possível dificuldade de muitos envolvidos na empresa chegarem a um consenso na tomada de decisões (L. F. Correia, et al., 2011).

No que se refere ao Chairman/CEO, é a relevância da não dualidade do profissional que atua como CEO e presidente do Conselho de Administração. Isso por que, pela perspectiva da Teoria da Agência, a distinção entre as funções de presidente e CEO devem auxiliar na diminuição dos conflitos de agência. Bem como, admite que o Conselho de Administração, possa monitorar de modo mais eficiente os atos dos executivos, tendo em vista a redução de suas atribuições, exercendo menos tarefas complexas (Tzioumis, 2008; Qin, 2012).

Vale destacar que o Comitê Cadbury (Reino Unido)'1, por exemplo, para propor reformas nos modelos de governança do país, recomendou, no relatório de 1992, que os conselhos incluam mais diretores independentes, nomeados pelos membros dos conselhos de administração, e dessa forma, havendo uma separação entre os papéis de diretores executivos e não-executivos, sendo estes mais envolvidos no monitoramento dos diretores executivos (Lethbridge, 1997).

No âmbito internacional, Alfraih (2016) destaca que como resultado de suas pesquisas a relevância do conselho de administração e de suas características na promoção do disclosure das empresas. Em que, é relatado que a divulgação é fundamental para a eficácia dos mercados de capital, na qual uma implicação direta do seu estudo é de que essas características podem ser utilizadas como um indicador de melhor qualidade e de relatórios financeiros.

Torchia \& Calabrò (2016) realizaram uma análise para verificar a relação entre o conselho de administração (independência do conselho, tamanho e CEO-dualidade - Chief Executive Officer - além da transparência financeira e divulgação T\&D (treinamento e desenvolvimento). Na qual, suas conclusões revelam a importância de avaliar a eficácia dos mecanismos de governança das empresas em melhorar o nível de participação financeira T\&D. Em que, o autor corroborou com Khan, et al. (2013) ao fornecer algumas indicações

\footnotetext{
${ }^{1}$ Comitê constituído no Reino Unido em 1992, com intuito de evidenciar as responsabilidades de conselheiros e executivos na prestação de contas e transparência, em especial para atender aos objetivos dos proprietários.
} 
para as empresas a melhorar os mecanismos de governança interna, por exemplo a relevância da elevada proporção de administradores independentes.

\section{Estrutura de Propriedade e Controle}

Almeida et al. (2015) com o objetivo de investigar a relação entre a estrutura de propriedade, controle e o disclosure voluntário socioambiental nas maiores empresas brasileiras, verificaram que a aplicação do teste estatístico não apresentaram significância, indicando que a estrutura de propriedade não exerce influência sobre o disclosure socioambiental. Por outro lado, Bezerra et al. (2015) constataram uma relação inversa entre concentração acionária e disclosure voluntário, o que remete a relevância das pesquisas em torno dessas relações com intuito de compreender o impacto da Governança Corporativa no disclosure voluntário socioambiental.

Diante disso, estudos sobre a estrutura de propriedade e controle tem sido um tema enfatizado nos mercados de capitais, como exemplo, Campos (2006), afirma que em países nos quais a concentração de ações entre poucos investidores são mais elevadas, como é o caso do Brasil, diversas são as particularidade do mercado que podem influenciar na estrutura de propriedade, como também, vários são os efeitos dessa estrutura no desempenho, governança corporativa e assimetria da informação (Caixe \& Krauter, 2013).

Uma das primeiras discussões sobre a separação entre propriedade (acionistas) e controle (gestores) foi realizada por Smith (1989) no "The Wealth of Nations". Em que, o autor verificou a preocupação com a estrutura de propriedade, devido aos custos que podem vir a ocorrer caso o gestor não levasse em conta as necessidade dos acionistas. Ao passo que, Berle \& Means (1932), na pesquisa "The Modern Corporation and a Private Property", destacam o quanto as firmas estavam sentindo a dificuldade de mantê-las sob a custodia de apenas um proprietário, sendo que o controle estava sendo transferido para os gestores.

A estrutura de propriedade diz respeito à estrutura societária da companhia, tendo em vista que a porcentagem de ações de um acionista no que tange ao total de ações da firma, além da relação entre a quantidade de recursos alocados por acionistas internos (administradores) e externos (investidores sem atuação na administração) (Balassiano, 2012). Bem como, é enfatizada pelos seguintes aspectos: (i) a identidade do acionista majoritário, ou seja, categoria com controle acionário da firma, tais como famílias, governo, 
bancos, investidores institucionais, entre outros; (ii) além da concentração da propriedade, sendo às ações detidas por acionista ou grupo de acionistas (Campos, 2006).

Os conflitos de agência podem vir a impactar nas decisões de alocação de recursos e financiamento de uma companhia pela gestão. Sendo assim, o futuro da organização pode ser decidido pelos gestores e não pelos proprietários (investidores). A medida que, os interesses dos dois grupos nem sempre convergem, ou seja, os investidores correm o risco de que aspectos relevantes do dia-a-dia da organização sejam confiados aos administradores (Coutinho, et al., 2006; Jensen \& Meckling, 1976).

Nesse contexto, devem ser criados mecanismos (sistemas de monitoramento e incentivos) para garantir que o comportamento dos executivos esteja alinhado com o interesse dos acionistas, incorrendo em custos de agência, que incluem custos de monitoramento pelo principal e custos de comprometimento do agente (Jensen \& Meckling, 1976).

Levando-se em consideração os aspectos já enfatizados sobre os conflitos entre a gestão e os proprietários, a governança corporativa surge como mecanismo de auxílio à boa gestão, em que evidencia as distinções entre a propriedade e a administração das firmas. Ou seja, sabendo-se que proprietários são os acionistas, os conselheiros e executivos são responsáveis pela administração e satisfação dos anseios dos proprietários.

Deve-se ter atenção para que não haja uma proporção exacerbante de dimensões de governança com pouca significância, bem como, não desmerecer dimensões que de fato tragam contribuições (Bebchuk \& Weisbach, 2010). Entre tais dimensões, destacam-se os direitos dos acionistas, a estrutura de propriedade e o conselho de administração, sendo elementos importantes para a acesso às informações, em especial das Informações Socioambientais (Silveira \& Barros, 2008; Dam \& Scholtens, 2013; Claessens \& Yurtoglu, 2013).

\section{Método}

\section{Coleta de Dados}

Os dados foram coletados no banco de dados da Economática $囚$, nos formulários de referência das empresas, por meio dos sites das próprias companhias e do site da Comissão 
de Valores Mobiliários (CVM), com todas as empresas abertas que negociaram suas ações na BM\&FBOVESPA, no período de 2010 a 2015.

A escolha do período a partir do ano de 2010 se justifica por causa da mudança do padrão contábil brasileiro para o padrão internacional das International Financial Reporting Standards (IFRS), com o advento da Lei ${ }^{0} 11.638 / 2007$, sendo que o processo de convergência foi completado em 2010.

Para compor a amostra, foram selecionadas as empresas que têm informações disponíveis sobre as variáveis investigadas e que negociam suas ações, ou seja, que estejam classificadas como ativas na bolsa no período selecionado. Ainda, a amostra é analisada em painel e apresenta-se balanceada, visto que esta técnica de amostragem pode apresentar um melhor resultado por evidenciar todos os dados para cada empresa da amostra, evitando com isso viés na análise. Dessa maneira, obteve-se como amostra final um total de 204 empresas, como descrito na Tabela 1.

Tabela 1

Amostra das empresas que negociaram ações na BM\&FBOVESPA

\begin{tabular}{lll}
\hline Critérios & Número de Empresas & $\%$ \\
\hline Empresas listadas na Bolsa & 386 & 100 \\
Empresas com ausência de informações & 182 & $47 \%$ \\
Amostra Final & 204 & $53 \%$ \\
\hline
\end{tabular}

Fonte: Dados da pesquisa (2010-2015).

\section{Análise de Dados}

\section{Variável dependente.}

Autores como Dye (2001), Hughes e Pae (2004), Pae (2005), Sousa et al (2014) e Almeida et al. (2015) realizam uma discussão sobre a efetividade de uma teoria unificada ou abrangente sobre disclosure voluntário. Nesse perspectiva, no que tange a variável dependente selecionada, para a dimensão disclosure de Informação socioambientais, é descrita a Tabela 2.

Tabela 2

Definição da dimensões das variáveis de Disclosure de Informações socioambientais

\begin{tabular}{l|l|l|l}
\hline Dimensão & Variável & Definição & Base Teórica \\
\hline
\end{tabular}


Disclosure de Empresas que divulgaram o

\section{Disclosure} voluntário
Informações relatório de sustentabilidade foi socioambient atribuído o valor 1 (um), caso ais contrário o (zero)
Guimarães

(2011);

Schultz, et al. (2012);

Comier \& Magnan

(2015); Clarkson et al.

(2013); Sousa et al. (2014); Bomfim, et al. (2015); Plumlee et al (2015); Torchia \& Calabrò (2016)

Fonte: Dados da pesquisa.

\section{Variáveis independentes.}

Quanto as variáveis independentes, serão enfatizadas por meio de duas dimensões (conselho de administração e estrutura de propriedade e controle), com base Com base em alguns autores, tais como, Berle \& Means (1932), Jensen e Meckling (1976), Smith (1989), Silveira e Barros (2008), Tzioumis (2008), Bebchuk e Weisbach (2010), L. F. Correia, et al. (2011), Qin (2012); Claessens e Yurtoglu (2013), P. R. Cunha e Politelo (2013), Dam e Scholtens (2013), Caixe e Krauter, (2013), Khan, et al. (2013), Jizi, et al. (2014); Alfraih (2016) e Torchia e Calabrò (2016). Como enfatizado na Tabela 3.

Tabela 3

Definição da dimensões das variáveis independentes Conselho de Administração e Estrutura de Propriedade e Controle

\begin{tabular}{l|l|l}
\hline Dimensão & Variável & Definição \\
\hline \multirow{2}{*}{$\begin{array}{l}\text { Administração } \\
\text { Adelho do }\end{array}$} & $\begin{array}{l}\text { Tamanho } \\
\text { Conselho }\end{array}$ & $\begin{array}{l}\text { Conselho formado por 5 (cinco) a 9 (nove) membros } \\
\text { recebeu o valor 1 (um), caso contrário o (zero) }\end{array}$ \\
\cline { 2 - 3 } & $\begin{array}{l}\text { Chairman/CEO } \\
\text { (Não dualidade) }\end{array}$ & $\begin{array}{l}\text { Conselho com pelo menos 20\% dos membros sendo } \\
\text { independentes recebeu o valor 1 (um), caso contrário o } \\
\text { (zero) }\end{array}$ \\
\hline (um), caso contrário o (zero)
\end{tabular}

Fonte: Dados da pesquisa. 
O parâmetro para coleta dos dados por meio de variáveis binárias (dummies) que indicam a presença (1) ou ausência (o) de cada variável em cada uma das empresas analisadas em cada ano, é de forma semelhante a Silva (2015) e Correia, Silva e Martins (2016), e com base nos diversos autores já supracitados. Além das recomendações do Instituto Brasileiro de Governança Corporativa (IBGC), para a variável Tamanho do Conselho (número ótimo, de acordo com a recomendação do IBGC, está entre 5 a 9 membros) e Independência (Conselho deve ter pelo menos 20\% dos membros sendo independentes).

\section{Variáveis de controle.}

As variáveis de controle são destacadas em duas dimensões: Características das Empresas e Desempenho Organizacional. Na qual, a base teórica é de acordo com Sousa, et al. (2014) e Almeida, et al. (2015). Como observado na Tabela 4.

Tabela 4

Definição da dimensões das variáveis de controle

\begin{tabular}{|c|c|c|}
\hline Dimensão & Variável & Definição \\
\hline \multirow{4}{*}{$\begin{array}{l}\text { Características } \\
\text { das Empresas }\end{array}$} & $\begin{array}{l}\text { Tamanho } \\
\text { empresa } \\
\text { Total) }\end{array}$ & Log natural do total de ativos das empresas \\
\hline & Internacionalização & $\begin{array}{l}\text { Empresa que emita ADR terá o valor } 1 \text { (um), caso } \\
\text { contrário o (zero) }\end{array}$ \\
\hline & $\begin{array}{l}\text { Governança } \\
\text { Corporativa }\end{array}$ & $\begin{array}{l}\text { Empresa listada em nível diferenciado de } \\
\text { governança da BM\&FBovespa (N1, N2 ou Novo } \\
\text { Mercado) recebeu valor } 1 \text { (um), caso contrário o } \\
\text { (zero) }\end{array}$ \\
\hline & Controle Acionário & $\begin{array}{l}\text { Empresa Estatal recebe o valor de } 1 \text { (um), se } \\
\text { privada o (zero) }\end{array}$ \\
\hline \multirow{2}{*}{$\begin{array}{l}\text { Desempenho } \\
\text { Organizacional }\end{array}$} & Alavancagem & Dívidas totais dividido pelo Ativo total \\
\hline & $\begin{array}{l}\text { Retorno sobre } \\
\text { Ativo }\end{array}$ & Lucro Líquido dividido sobre o Ativo total \\
\hline
\end{tabular}

Fonte: Dados da pesquisa.

As variáveis de controle foram selecionadas de acordo com a literatura de disclosure ambiental, são proxies que buscam explicar a divulgação das informações socioambientais. Com relação ao tamanho da empresa, espera-se que quanto maior o tamanho da empresa, maior seja o nível de disclosure (Souza, et al., 2014). A internacionalização, por sua vez, 
também requer uma maior transparência por parte das organizações, fazendo com que haja uma maior preocupação com o disclosure. Os níveis de governança representa a classificação de boas práticas de governança, o que pode mitigar os problemas com disclosure (Bomfim, et al., 2015). Com relação ao controle acionário, empresas com blockholders apresentam uma tendência a ter um menos disclosure de informações voluntárias (Ghazali, 2007). Com relação ao desempenho, espera-se que empresas com melhor performance possuam também uma melhor divulgação de informações (Verrechia, 2001; Bomfim, et al., 2015).

A partir da seleção das variáveis do estudo, apresenta-se abaixo a Equação 1 referente ao modelo econométrico, evidenciado em Regressão Logística Binária, para análise da relação entre a variável representativa do disclosure voluntário (Informações socioambientais), em relação ao conselho de administração e estrutura de propriedade e controle:

$$
\log \left(\frac{\pi}{1-\pi}\right)=\beta_{0}+\beta_{1} X_{1}+\cdots \beta_{n} X_{n}+\varepsilon
$$

Em que, $\pi$ diz respeito a probabilidade de um determinado evento de interesse, ou seja, na Regressão Logit, pela método de modelagem estatística, na qual a variável dependente é dicotômica, Disclosure de Informações socioambientais, em que caso positivo recebeu valor 1 (um), caso contrário o (zero). Ainda, $x_{1}, x_{2}, \ldots x_{n}$ são as variáveis independentes, e $\beta_{1}, \beta_{2}, \ldots \beta_{n}$ são os parâmetros do modelo logit, bem como $\varepsilon$ é o erro aleatório.

\section{Desenvolvimento das hipóteses estatísticas.}

O presente estudo investiga como o conselho de administração pode afetar o nível de disclosure voluntário das companhias brasileiras. De acordo com Bezerra et al. (2015) o conselho tem duas funções importantes que é reafirmar as decisões e monitorar a gestão, além disso ele é composto tanto por membros externos como por membros internos eleitos para defender o direito de todos os acionistas, uma característica do conselho determinantes para a sua eficácia é o seu tamanho. Nesse sentido, torna-se importante verificar se o conselho e a sua composição se relaciona com o nível de disclosure das companhias, levando em consideração autores como Silveira e Barros (2008), Tzioumis (2008); L. F. Correia, et al. (2011), Bebchuk e Weisbach (2011), Qin (2012); Claessens e Yurtoglu (2013), P. R. Cunha e Politelo (2013), Khan, et al. (2013), Jizi, et al. (2014); Alfraih (2016) e Torchia e Calabrò (2016). Diante disso, pretende-se verificar as seguintes hipóteses: 
H1: Existe relação positiva entre número ótimo de membros nos conselho (5 a 9 membros de acordo com o IBGC) e o Disclosure de Informações socioambientais das empresas abertas.

H2: Existe relação positiva entre a independência dos membros do conselho e o Disclosure de Informações socioambientais das empresas abertas.

H3: Existe relação positiva entre o presidente do conselho não ser o CEO e o Disclosure de Informações socioambientais das empresas abertas.

No que tange a estrutura de propriedade e controle também busca-se investigar se esta pode influenciar na divulgação de informações voluntárias por parte das empresas. De acordo com Bezerra et al. (2015) a composição acionária, por meio de acionistas controladores, e o perfil deles pode influenciar no nível de disclosure das empresas. Dam e Scholtens (2013) em seu estudo com empresas multinacionais europeias verificou a relação entre o controle acionário e a divulgação voluntária, identificaram que quanto maior a concentração menor o nível de divulgação. Portanto, é relevante analisar se há alguma relação entre a estrutura de propriedade e controle das empresas e a divulgação voluntária destas, como enfatizado por Campos (2006) e Claessens \& Yurtoglu (2013). Sendo assim, tem-se mais as seguintes hipóteses:

H4: Há relação positiva entre a emissão de ações ordinárias pelas empresas e o Disclosure de Informações socioambientais das empresas abertas.

H5: Há relação positiva entre a presença de acionista controlador com menos de 50\% de direito de voto e o Disclosure de Informações socioambientais das empresas abertas.

H6: Há relação positiva entre a proporção das ações preferenciais pelas ações ordinárias das empresas e o Disclosure de Informações socioambientais das empresas abertas.

\section{Discussão e Resultados}




\section{Análise Descritiva dos Resultados}

A estatística descritiva das variáveis da amostra selecionada evidencia a média, desvio padrão e a mediana, das 204 empresas analisadas no período de 2010 a 2015 conforme é apresentado na Tabela 5. Na qual, é observado que menos de 50\% das companhias selecionadas divulgam Informações socioambientais (cerca de 47\%). Esse resultado é similar ao obtido por L. M. D. S. Cunha e Ribeiro (2016), que verificou que no período de 2010 a 2014, apenas 58\% das empresas do setor de energia elétrica divulgavam informação a respeito de provisões ambientais.

A medida que, das 204 empresas que compuseram a análise, verificou-se que $75 \%$ delas apresentaram conselhos de administração que possuem a quantidade mínima de membros recomendada pelo IBGC, corroborando com o resultado obtido por Guimarães (2011). A independência dos membros do conselho foi identificada em cerca de $57 \%$ das empresas analisadas, ou seja, mais da metade das empresas analisadas tem cerca de $20 \%$ de seus conselheiros eleitos/escolhidos de forma independente sem influência dos acionistas controladores, isso é uma medida que busca assegurar que o conselho possa tomar decisões mais voltadas para a eficiência do desempenho das organizações e não apenas do que for melhor para o acionista controlador.

Nesse aspecto, a variável Chairman/CEO, apresentou o maior percentual, em relação às demais variáveis do conselho de administração, com cerca de $81 \%$, essa variável representa a não dualidade do CEO nas companhias, o que é visto como uma característica positiva do mercado, uma vez que esta pode ser uma forma de proteção dos interesses de todos os acionista (majoritários e minoritários).

Com relação as variáveis que compõem a estrutura de propriedade das companhias, ao observar a composição acionária das empresas, percebe-se que metade destas emitem somente ações do tipo ordinária, que dão direito a voto, cerca de $55 \%$. Com relação ao perfil dos controladores destas empresas, metade deles possuem menos de 50\% do capital votante, ou seja, é possível observar que ainda há uma alta concentração acionária do capital destas empresas. E com relação a proporção das ações preferenciais que representam o fluxo de caixa e as ações ordinárias que representam controle, observou-se com relação aos acionistas controladores destas companhias que a maioria dão preferência à ações que dão poder de voto, em detrimento de ações que gerem fluxo de caixa. 
No que se refere as características das empresas, com relação ao nível de internacionalização das companhias, medido por meio da emissão de ADRs, obteve-se um percentual de apenas 10\%, ou seja, apenas 10\% das companhias que compõe a amostra negociam fora do Brasil. Todavia, a participação em níveis diferenciados de governança, de acordo com a classificação da Bovespa, foi de 63\% da amostra analisada, essa classificação certifica que estas companhias tem uma maior preocupação com a governança corporativa.

Tabela 5

Estatística descritiva referente ao Disclosure de Informações socioambientais, Conselho de Administração e Estrutura de Propriedade e Controle

\begin{tabular}{llll}
\hline Variáveis & Média & Desvio Padrão & Mediana \\
\hline Informações socioambientais & 0,472 & 0,499 & 0,000 \\
Tamanho do Conselho & 0,756 & 0,430 & 1,000 \\
Independência & 0,571 & 0,495 & 1,000 \\
Chairman/CEO & 0,810 & 0,392 & 1,000 \\
Ações ON & 0,555 & 0,497 & 1,000 \\
Participação controlador & 0,489 & 0,500 & 0,000 \\
Fluxo de caixa/Controle & 0,102 & 0,302 & 0,000 \\
Log Ativo Total & 14,885 & 1,857 & 15,022 \\
Internacionalização & 0,107 & 0,309 & 0,000 \\
Governança Corporativa & 0,633 & 0,482 & 1,000 \\
Controle Acionário & 0,069 & 0,254 & 0,000 \\
Alavancagem & 1,038 & 4,071 & 0,595 \\
Retorno sobre ativo & 0,055 & 2,288 & 0,033 \\
\hline
\end{tabular}

Fonte: Dados da pesquisa (2010-2015). 1224 Obs.

Além disso, cerca de $7 \%$ das empresas analisadas, são companhias estatais, para Almeida et al (2015) esse percentual foi de 17\%, porém a sua amostra se limitou as 100 maiores companhias e apenas no ano de 2012. Com relação a alavancagem, na média apresentada no período, foi relativamente alta, superior a $100 \%$, mas considerando a mediana esse valor diminui para cerca de 60\%. Ao passo que, o retorno médio apresentado pelas companhias foi em torno dos $5 \%$, ou seja, essa é a remuneração média de seus investidores.

\section{Análise Inferencial dos Resultados}


A Tabela 6 evidencia a regressão do disclosure voluntário das informações socioambientais em relação a composição do conselho de administração, estrutura de propriedade, além das variáveis de controle. Dessa maneira, pode-se identificar que no modelo 1 e modelo 2 as variáveis são conjuntamente significativas para explicar a probabilidade de a composição do conselho de administração e estrutura de propriedade influenciar na divulgação de informações voluntárias, pelo LR de 47.37 e 26.48, respectivamente. Ainda, o valor da estatística da probabilidade F índica que não há a rejeição da hipótese de que todos os coeficientes sejam iguais a 0.

Quanto aos modelos 3, 4 e 5 são os que melhores representam as relações analisadas, devido ao Pseudo $\mathrm{R}^{2}$ mais elevados. Isso porque, são modelos que evidenciaram as variáveis de controle. Com isso, destaca-se o modelo 5, na qual 21\% da variação dependente pode ser explicada pelas variáveis independentes. Ao passo que, no que tange a descrição dos valores corretamente classificados, o modelo pode prevê 70,52\% de observações de forma correta.

No que se refere aos valores dos coeficientes, a independência do conselho de administração, ou seja, conselho com pelo menos 20\% dos membros sendo independentes, como requerido pelo nível mais elevado de governança corporativa, perde a significância quando são acrescentadas as variáveis de controle, visto que possui relação positiva e significante em 1\% com o nível de disclosure voluntário, para as empresas selecionadas e no período analisado, no primeiro modelo, mas para os demais modelos que incluíam as variáveis de controle não obteve-se significância estatística. Sendo assim, não é possível fazer inferências sobre tal impacto da independência sobre a divulgação voluntária socioambiental considerando esse cenário.

Com relação a variável Chairman/CEO apresentou relações positivas e significantes ao nível de $5 \%$ em todos os casos enfatizados. Tais relações mostram a relevância do conselho cujo presidente não deve ser o CEO (L. F. Correia, et al., 2011; Khan, et al., 2013; Bomfim, et al., 2015; Torchia \& Calabrò, 2016; Alfraih, 2016) para a divulgação de informações socioambientais para as companhias selecionadas na amostra. Ou seja, a não dualidade dos gestores, impacta no aumento da divulgação de informações socioambientais, isso é verificado por meio de seu coeficiente $(0,928)$ e conforme o modelo é controlado com variáveis relativas as características das empresas como tamanho e desempenho, esse impacto gerado pela não dualidade diminui, passando a ser de $(0,503)$.

Além disso, pela estrutura de propriedade, a participação do controlador foi a única variável que apresentou significância estatística, isso em todos modelos evidenciados, onde 
o impacto inicialmente identificado foi de $(-0,62)$ e conforme o modelo foi controlado pelas características da companhia o fator de impacto na explicação da relação aumentou par (o,66) ), importante destacar que a relação obtida foi oposta a esperada, visto que acreditavase que empresas com uma maior pluralidade acionária tivesse um efeito positivo sobre a divulgação de informações voluntárias.

Essas relações negativas verificadas, corroboram Bezerra, et al. (2015), que por sua vez observou uma relação inversa entre concentração acionária e extensão do disclosure voluntário. Diante disso, os autores afirmam que uma possível explicação é a adoção obrigatória das IFRS para as demonstrações contábeis consolidadas de firmas abertas em 2010, e para as demonstrações contábeis individuais, desde janeiro de 2008, podendo ter influenciado na divulgação de informações socioambientais independente dos controladores das companhias selecionadas possuírem menos que 50\% das ações com direito ao voto. No mercado Malaio, ao contrário do percebido na presente amostra, identificou que empresas com maior concentração apresentou um nível de divulgação de informações socioambientais bem inferior Ghazali (2007).

Tabela 6

Regressões Logit referentes ao Disclosure de Informações socioambientais em relação ao Conselho de Administração e Estrutura de Propriedade e Controle

\begin{tabular}{|c|c|c|c|c|c|}
\hline Variáveis & Modelo [1] & Modelo [2] & $\begin{array}{l}\text { Modelo } \\
\text { [3] }\end{array}$ & Modelo [4] & $\begin{array}{l}\text { Modelo } \\
{[5]}\end{array}$ \\
\hline Constante & $\begin{array}{l}-1,010^{* *} \\
(-5,81)\end{array}$ & $\begin{array}{l}0,072 \\
(0,72)\end{array}$ & $\begin{array}{l}-9,900^{* *} \\
(-11,61)\end{array}$ & $\begin{array}{l}-9,180^{* *} \\
(-10,88)\end{array}$ & $\begin{array}{l}-9,337^{* *} \\
(-10,84)\end{array}$ \\
\hline Tamanho do Conselho & $\begin{array}{l}-0,030 \\
(-0,21)\end{array}$ & $\begin{array}{l}- \\
-\end{array}$ & $\begin{array}{l}-0,058 \\
(-0,33)\end{array}$ & $\begin{array}{l}- \\
-\end{array}$ & $\begin{array}{l}-0,114 \\
(-0,64)\end{array}$ \\
\hline Independência & $\begin{array}{l}0,278^{*} \\
(2,18)\end{array}$ & - & $\begin{array}{l}-0,053 \\
(-0,32)\end{array}$ & - & $\begin{array}{l}0,071 \\
(0,40)\end{array}$ \\
\hline Chairman/CEO & $\begin{array}{l}0,928^{* *} \\
(5,69)\end{array}$ & $\begin{array}{l}- \\
-\end{array}$ & $\begin{array}{l}0,558^{* *} \\
(2,98)\end{array}$ & $\begin{array}{l}- \\
-\end{array}$ & $\begin{array}{l}0,503^{* *} \\
(2,70)\end{array}$ \\
\hline Ações ON & - & $\begin{array}{l}0,236 \\
(1,80)\end{array}$ & - & $\begin{array}{l}-0,142 \\
(-0,84)\end{array}$ & $\begin{array}{l}-0,179 \\
(-1,00)\end{array}$ \\
\hline Participação controlador & - & $\begin{array}{l}-0,624^{* *} \\
(-4,97)\end{array}$ & - & $\begin{array}{l}-0,662^{* *} \\
(-4,48)\end{array}$ & $\begin{array}{l}-0,641^{* *} \\
(-4,30)\end{array}$ \\
\hline Fluxo de caixa/Controle & - & $\begin{array}{l}-0,111 \\
(-0,55)\end{array}$ & $\begin{array}{l}- \\
-\end{array}$ & $\begin{array}{l}0,160 \\
(0,67)\end{array}$ & $\begin{array}{l}0,151 \\
(0,63)\end{array}$ \\
\hline Log Ativo Total & - & $\begin{array}{l}- \\
-\end{array}$ & $\begin{array}{l}0,610^{* *} \\
(10,74)\end{array}$ & $\begin{array}{l}0,599^{* *} \\
(10,51)\end{array}$ & $\begin{array}{l}0,590^{* *} \\
(10,34)\end{array}$ \\
\hline Internacionalização & $\begin{array}{l}- \\
-\end{array}$ & $\begin{array}{l}- \\
-\end{array}$ & $\begin{array}{l}0,339 \\
(1,18)\end{array}$ & $\begin{array}{l}0,335 \\
(1,15)\end{array}$ & $\begin{array}{l}0,342 \\
(1,17)\end{array}$ \\
\hline
\end{tabular}




\begin{tabular}{llllll} 
Governança Corporativa & - & - & 0,282 & $0,663^{* *}$ & $\begin{array}{l}0,566^{* *} \\
\text { Controle Acionário }\end{array}$ \\
\cline { 2 - 4 } & - & - & $(1,59)$ & $(3,81)$ & $(2,97)$ \\
Alavancagem & - & - & $0,968^{* *}$ & $0,789^{*}$ & $0,763^{*}$ \\
& - & - & $(2,98)$ & $(2,39)$ & $(2,29)$ \\
Retorno sobre ativo & - & - & $-0,003$ & $-0,023$ & $-0,015$ \\
& - & - & $(-0,06)$ & $(-0,42)$ & $(-0,30)$ \\
Pseudo R & - & - & 0,112 & 0,115 & 0,127 \\
LR Estat. F & $2 \%$ & $2 \%$ & $20 \%$ & $21 \%$ & $21 \%$ \\
Prob. F & 47.37 & 26.48 & 328.43 & 343.95 & 351.95 \\
Classificação correta & 0.0000 & 0.0000 & 0.0000 & 0.0000 & 0.0000 \\
Observações & $56.40 \%$ & $57.39 \%$ & $70.27 \%$ & $69.28 \%$ & $70.52 \%$ \\
\hline
\end{tabular}

Fonte: Dados da pesquisa (2010-2015). Notas: Estatística Z entre parênteses. * Estatisticamente significante a 1\%, ${ }^{* *}$ Estatisticamente significante a $5 \%$.

Nesse contexto, quanto as variáveis de controle, apenas variáveis relativas as características das companhias apresentaram influência sobre a divulgação socioambiental. O tamanho das empresas, representado pelo Log do Ativo Total, em todos os modelos, nas quais foram destacados, apresentaram relações positivas e significantes, assim como identificado por Souza et al. (2014) e Bomfim, et al. (2015) em seus estudos. Bem como, o controle pelos níveis diferenciados de Governança Corporativa nos modelos 4 e 5, como esperado. Do mesmo modo, o controle estatal também apresentou relações positivas e significantes, devido ao fato de que tais empresas, são submetidas a agências reguladoras, obtendo um maior controle sobre suas operações, com fiscalizações mais elevadas e pelo maior número de entrega de relatórios, ratificando os resultados da pesquisa de Almeida et al. (2015).

\section{Conclusões}

Este estudo teve por objetivo analisar o impacto da Governança Corporativa (representada pelo conselho de administração e estrutura de propriedade e controle) no disclosure voluntário das Informações Socioambientais das companhias brasileiras listadas na BM\&FBovespa. Em que, apenas $47 \%$ das firmas divulgaram as Informações Socioambientais, no período e com a amostra analisada. Com isso, quanto as hipóteses estatísticas, relevantes para responder ao objetivo da pesquisa, observou-se os seguintes resultados: 
Quanto as três primeiras hipóteses de pesquisa, sobre as relações positivas entre a composição do conselho de administração e o disclosure voluntário de informações socioambientais, verifica-se que pelos coeficientes das regressões, que a independência do conselho apresentou significância estatística para primeiro modelo, ou seja, sem que sejam enfatizadas as variáveis de controle.

Além disso, na variável Chairman/CEO também foram detectadas relações positivas e significantes ao nível de $5 \%$ em seus respectivos modelos. Ou seja, o fato de que o presidente do conselho não deve ser o $\mathrm{CEO}$, é um aspecto imprescindível da Governança Corporativa para que haja divulgação de Informações Socioambientais das companhias abertas (Silveira \& Barros, 2008; Tzioumis, 2008; L. F. Correia, et al., 2011; Bebchuk \& Weisbach, 2011; Qin, 2012; Claessens \& Yurtoglu, 2013; P. R. Cunha \& Politelo, 2013; Khan, et al., 2013; Jizi, et al., 2014; Alfraih, 2016; Torchia \& Calabrò, 2016).

No que se refere as três hipóteses estatísticas sobre as relações positivas entre a estrutura de propriedade e controle e o disclosure voluntário de Informações Socioambientais, apenas a variável Participação do Controlador apresentou significância estatística, isso em todos os modelos nas quais foram enfatizados. No entanto, com relações negativa, ao contrário do esperado. Uma possível justificativa, diz respeito as ideias de Bezerra, et al. (2015), de que a adoção obrigatória das IFRS para as firmas abertas em 2010, no Brasil, podem ter impactado na disponibilização de Informações Socioambientais mesmo que os controladores das companhias selecionadas possuíssem mais que 50\% das ações com direito ao voto.

Por fim, atenta-se para as limitações da pesquisa, tanto pelo período de análise ser entre 2010 a 2015, quanto pela limitação das organizações selecionadas para amostra, ou seja, o estudo não deve ser generalizado. No entanto, não deve ser invalidado, tendo em vista suas principais contribuições, tais como, as relações entre o conselho de administração, estrutura de propriedade e controle com o disclosure voluntário de Informações Socioambientais. Assim, como sugestão para futuras pesquisas, recomenda-se a inserção de mais variáveis explicativas relacionadas a Governança Corporativa, proporcionando a captação de maiores características sobre o assunto. 


\section{Referências}

Alfraih, M. M. (2016). The effectiveness of board of directors' characteristics in mandatory disclosure compliance. Journal of Financial Regulation and Compliance, 24.

Almeida, T. A., Santos, L. M. F., Cabral, A. C. A., Santos, S. M., \& Pessoa, M. N. M. (2015). Estrutura de propriedade e Disclosure econômico e socioambiental nas maiores empresas do Brasil. REPeC, 9(4), 362-379.

Aranha, C. E., Rossoni, L., \& Mendes-da-Silva, W. (2016). Capital social do Conselho de administração e desempenho de empresas de capital aberto brasileiras. RAM - Rev. Adm. Mackenzie, 17(1), 15-39.

Balassiano, M. G. (2012). Estrutura de propriedade e Teoria da agência: um estudo de empresas brasileiras e seus diferentes tipos de controladores. (Dissertação de Mestrado, Administração). Fundação Getúlio Vargas, Rio de Janeiro.

Baysinger, B. D., \& Butler, H. N. (1985). Corporate governance and the board of directors: performance effects of changes in board composition. Journal of Law, Economics, \& Organization, 1(1), 101-124.

Bebchuk, A., \& Weisbach, M. (2010). The state of corporate governance research. The Review of Financial Studies, 23(3).

Berle, A., \& Means, G. (1932). The modern corporation and private property. New York: Macmillan.

Bezerra, P. C. S., Lustosa, P. R. B., Sales, I. C. H., \& Fernandes, B. V. R. (2015). Estrutura de propriedade, Conselho de administração e Disclosure voluntário: Evidências de empresas brasileiras de capital aberto. Revista Universo Contábil, 2, 25-46.

Bomfim, E. T., Teixeira, W. D. S., \& Monte, P. A. (2015). Relação entre o disclosure da sustentabilidade com a governança corporativa: Um estudo nas empresas listadas no Ibrx-100. Sociedade, Contabilidade e Gestão, 10(1), 6-28. 
Caixe, D. F., \& Krauter, E. A. (2013). Influência da estrutura de propriedade e controle sobre o valor de mercado corporativo no Brasil. Revista Contabilidade \& Finanças, 24(62), 142153.

Campos, T. L. C. (2006). Estrutura da propriedade e desempenho econômico: uma avaliação empírica para as empresas de capital aberto no Brasil. Revista de Administração da USP, 41(4), 369-380.

Claessens, S., \& Yurtoglu, B. (2013). Corporate governance in emerging markets: a survey. Emerging Markets Review, 15, 1-33.

Clarkson, P., Fang, X., Li, Y., \& Richardson, G. (2013). The relevance of environmental disclosure: are such disclosures incrementally informative? J. Acc. Public Policy, 32, 410431.

Correia, L. F., Amaral, H. F., \& Luvet, P. (2011). Um índice de avaliação da qualidade da governança corporativa no Brasil. Revista Contabilidade e Finanças-USP, São Paulo, 22(55), 45-63.

Correia, T. S., Silva, M. N. F., \& Martins, O. S. (2016). Qualidade da governança corporativa das empresas no mercado brasileiro de capitais. ConTexto, 16(33), 4-19.

Coutinho, E. S. Amaral, H. F., \& Bertucci, L. A. (2006). O impacto da estrutura de propriedade no valor de mercado de empresas Brasil. Revista de Administração da USP, 41(2), 197-207.

Cunha, P. R., \& Politelo, L. (2013). Determinantes do nível de governança corporativa das empresas brasileiras de capital aberto do setor de consumo cíclico da BM\&FBOVESPA. Advances in Scientific and Applied Accounting, São Paulo, 6(2), 211-235.

Cunha, L. M. D. S., \& Ribeiro, M. S. (2016). A divulgação de provisões e passivos contingentes ambientais pelas empresas do setor de energia elétrica em comparação ao desenvolvimento da normatização da evidenciação contábil. Revista Universo Contábil, 12(4), 86-106. 
Comier, D., \& Magnan, M. (2015). The economic relevance of environmental disclosure and its impact on corporate legitimacy: An empirical investigation. Business Strategy and the Environment, 24(6), 431-450.

Dam, L., \& Scholtens, B. (2013). Ownership concentration and CSR policy of European multinational enterprises. Journal of Business Ethics, 118(1), 117-126.

Dye, R. A. (2001). An evaluation of 'essays on disclosure' and the disclosure literature in accounting. Journal of Accounting and Economics. New York: 32(13), 181-235.

Ghazali, N. A. M. (2007). Ownership structure and corporate social responsibility disclosure: some Malaysian evidence. Corporate Governance, 7(3), 251-266.

Guimarães, R. F. S. C. (2011). Oportunidades de crescimento e a importância da monitorização exercida pelo Conselho de Administração. (Dissertação de Mestrado, Finanças). Universidade do Minho, Escola de Economia e Gestão, Portugal.

Holtz, L., \& Sarlo Neto, A. (2014). Efeitos das características do Conselho de administração sobre a qualidade da informação contábil no Brasil. Revista Contabilidade \& Finanças USP, 25(66), 255-266.

Hughes, J. S., \& Pae, S.. (2004). Voluntary disclosure of precision information. Journal of Accounting and Economics. New York: 37(2), 261-289.

Instituto Brasileiro de Governança Corporativa. Governança Corporativa. Recuperado de http://www.ibgc.org.br/

Igarashi, D. C. C, Igarashi, W., Lima, E. C., Dalbello, L, \& Hercos Junior, J. B. (2010). Análise do alinhamento entre o balanço social e o relatório de sustentabilidade dos três maiores bancos em atividade no Brasil. ConTexto, 10(18), 34-48.

Jamali, D., Asem M. S., \& Myriam, R. (2008). Corporate governance and corporate social responsibility synergies and interrelationships. Corporate Governance. 16(5), 443-459.

Jensen, M. C., \& Meckling, W. H. (1976). Theory of the firm: managerial behavior, agency costs and ownership structure. Journal of Financial Economics, 3(4), 305-360. 
Jizi, M.I., Salama, A., Dixon, R., \& Stratling, R.. (2014). Corporate governance and corporate social responsibility disclosure: Evidence from the US banking sector. Journal of Business Ethics. 125, 601-615.

Khan, A., Muttakin, M.B. \& Siddiqui, J. J. (2013). Corporate governance and corporate social responsibility disclosures: Evidence from an emerging economy. Journal of Business Ethics, 114(2), 207-223.

Lei $n^{o}$ 6.404. (1976). Dispõe sobre as Sociedades por Ações. Recuperado em http://www.planalto.gov.br/ccivil_o3/leis/L6404consol.htm

Lethbridge, E.. (1997). Governança corporativa. Revista do BNDES. Recuperado de http://www.ppge.ufrgs.br/Giacomo/arquivos/gov-corp/lethbridge-1997.pdf

Pae, S.. (2005). Selective disclosures in the presence of uncertainty about information endowment. Journal of Accounting and Economics. New York: 39(3), 383-409.

Plumlee, M., Brown, D., Hayes, R. M., R., \& Marshall, S. (2015). Voluntary environmental disclosure quality and firm value: Further evidence. J.Account. Public Policy. 34(4), 336361.

Qin, B. (2012). The influence of firm and executive characteristics on performance-vested stock option grants. International Business Review. 21(5), 906-928.

Schultz, C. A., Marques, T. O., Murcia, F. D., \& Hofer, E. (2012). Disclosure voluntário de informações ambientais, econômicas e sociais em cooperativas do setor agropecuário. Teoria e Prática em Administração, 2(2), 56-77.

Silveira, A. M., \& Barros, L. (2008). Determinantes da qualidade da governança corporativa das companhias abertas brasileiras. Revista Eletrônica de Administração-READ, Porto Alegre, 14(3).

Silva, C. C. S. (2015) Análise do reflexo da qualidade de Governança Corporativa no processo de avaliação de empresas. (Dissertação Mestrado, Administração). Universidade Federal da Paraíba, João Pessoa.

Smith, A. (1989). The Wealth of Nations. Blackstone Audio. 
Soliman, M. M., El Din, M. B., \& Sakr, A. (2012). Ownership structure and Corporate Social Responsibility (CSR): An empirical study of the listed companies in Egypt. The International Journal of Social Sciences. 5(1).

Sousa, C. B., Silva, A. S., Ribeiro, M. S., \& Weffort, E. F. J. (2014). Valor de Mercado e Disclosure Voluntário: Estudo Empírico em Companhias Listadas na BM\&FBOVESPA. Revista Ambiente Contábil, 6(2), 94-115.

Torchia, M., \& Calabrò, A. (2016). Board of directors and financial transparency and disclosure. Evidence from Italy. Corporate Governance, 16(3), 593 - 608.

Tzioumis, K. (2008). Why do firms adopt ceo stock options? Evidence from the united states. Journal of Economic Behavior \& Organization, 68(1), 100-111.

Verrecchia, R. E. (2001). Essays on disclosure. Journal of Accounting and Economics. New York: 32(13), 97-180.

Williamson, O. E. (1983). Organization form, residual claimants, and corporate control, Journal of Law and Economlics, 351.

Yusoff, H., Jamal, A. D. A., \& Darus, F. (2016). Corporate governance and corporate social responsibility disclosures: An Emphasis on the CSR Key Dimensions. Journal of Accounting and Auditing: Research \& Practice. 